\title{
Spatiotemporal Characterization of the Urban Expansion Patterns in the Yangtze River Delta Region
}

\author{
Ziqi Yu ${ }^{1,2}$, Longqian Chen ${ }^{1,2}$, Long $\mathrm{Li}^{1,2,3, *}$, Ting Zhang ${ }^{1,2}$, Lina Yuan ${ }^{4} \mathbb{D}^{\text {, Ruiyang Liu }}{ }^{5}$, Zhiqiang Wang ${ }^{1,2}$, \\ Jinyu Zang ${ }^{1,2}$ and Shuai Shi ${ }^{6}$
}

1 Research Center for Transformation Development and Rural Revitalization of Resource-Based Cities in China, China University of Mining and Technology, Daxue Road 1, Xuzhou 221116, China; ziqi.yu@cumt.edu.cn (Z.Y.); chenlq@cumt.edu.cn (L.C.); tingzhang@cumt.edu.cn (T.Z.); zq.wang@cumt.edu.cn (Z.W.); jinyu.zang@cumt.edu.cn (J.Z.)

2 School of Public Policy and Management, China University of Mining and Technology, Daxue Road 1, Xuzhou 221116, China

3 Department of Geography, Earth System Sciences, Vrije Universiteit Brussel, Pleinlaan, 2, 1050 Brussels, Belgium

4 Key Laboratory of Geographic Information Science (Ministry of Education), School of Geographic Sciences, East China Normal University, Shanghai 200241, China; lnyuan@geo.ecnu.edu.cn

5 School of Environment and Spatial Informatics, China University of Mining and Technology, Daxue Road 1, Xuzhou 221116, China; ruiyang.liu@cumt.edu.cn

6 School of Resources and Geoscience, China University of Mining and Technology, Daxue Road 1, Xuzhou 221116, China; shuai.shi@cumt.edu.cn

* Correspondence: long.li@cumt.edu.cn; Tel.: +86-516-8359-1327

check for updates

Citation: Yu, Z.; Chen, L.; Li, L.; Zhang, T.; Yuan, L.; Liu, R.; Wang, Z.; Zang, J.; Shi, S. Spatiotemporal Characterization of the Urban Expansion Patterns in the Yangtze River Delta Region. Remote Sens. 2021, 13, 4484. https://doi.org/10.3390/ rs13214484

Academic Editors: Lin Li, Mengjun Kang and Min Weng

Received: 28 September 2021 Accepted: 4 November 2021 Published: 8 November 2021

Publisher's Note: MDPI stays neutral with regard to jurisdictional claims in published maps and institutional affiliations.

Copyright: (c) 2021 by the authors. Licensee MDPI, Basel, Switzerland. This article is an open access article distributed under the terms and conditions of the Creative Commons Attribution (CC BY) license (https:// creativecommons.org/licenses/by/ $4.0 /)$.

\begin{abstract}
Characterizing urban expansion patterns is of great significance to planning and decisionmaking for urban agglomeration development. This study examined the urban expansion in the entire Yangtze River Delta Region (YRDR) with its land-use data of six years (1995, 2000, 2005, 2010, 2015, and 2018). On the basis of traditional methods, we comprehensively considered the four aspects of urban agglomeration: expansion speed, expansion difference, expansion direction, and landscape pattern, as well as the interconnection of and difference in the expansion process between each city. The spatiotemporal heterogeneity of urban expansion development in this region was investigated by using the speed and differentiation indices of urban expansion, gravity center migration, landscape indices, and spatial autocorrelations. The results show that: (1) over the 23 years, the expansion of built-up land in the Yangtze River Delta Region was significant, (2) the rapidly expanding cities were mainly located along the Yangtze River and coastal areas, while the slowly expanding cities were mainly located in the inland areas, (3) the expansion direction of each city varied and the gravity center of the urban agglomeration moved toward the southwest, and (4) the spatial structure of the region became more clustered, the shape of built-up land turned simpler, and fragmentation decreased. This study unravels the spatiotemporal change of urban expansion patterns in this large urban agglomeration, and more importantly, can serve as a guide for formulating urban agglomeration development plans.
\end{abstract}

Keywords: urban expansion; spatiotemporal pattern; gravity center migration; Yangtze River Delta Region

\section{Introduction}

As the world population and economy continue to grow, urban agglomerations have become a new trend in global urbanization. Managing and quantifying the expansion of urban agglomerations is a major challenge in this century [1,2]. Urban agglomerations are usually characterized by different population sizes [3], economic structures [4], landscape patterns [5], and road network densities [6,7]. These, together with many other factors, often result in a series of severe social and environmental problems [8] and geohydrological risks [9], ranging from increased temperatures [10,11] to polluted air [12], polluted water [13], and flood risk [14]. Around 1899, the urban expansion of Bamenda 
Town gradually invaded and transformed the hillside system, resulting in an increased dislocation of the relationship between human settlements and the environment [15]. The urban expansion of Dakar, Senegal, and the Greater Concepcion Metropolitan Area, Chile, was through the occupation of land that was irregular and unsuitable for natural processes and was often accompanied by poor urban management, leading to the out-of-control urbanization process and triggering the risk of natural disasters such as floods $[16,17]$. In this context, researchers have paid heed to urban agglomerations and their associated issues, among which is their urban expansion patterns. A good understanding of their urban expansion patterns can facilitate the formulation of urban agglomeration development plans by decision makers.

Research on urban spatial clusters began as early as the 1920s, using megalopolis [18], urban agglomeration $[19,20]$, city group, and city cluster to describe such urban spatial organization [21]. Urban agglomerations were initially defined as a central city and several surrounding towns [22]. The study on Chinese urban agglomerations began with the concept of urban agglomerations proposed by Zhenhua [23]. He defined urban agglomerations as the aggregation of multiple cities with different economic structures, different population sizes, and different characteristics. Many cities in the world have experienced rapid expansion, gradually developing into urban agglomerations, e.g., the Guwahati urban agglomeration [24], Ranchi urban agglomeration [25], the Kolkata agglomeration [26], the Yangtze River Delta urban agglomeration [27], the Pearl River Delta [28], and the BeijingTianjin-Hebei urban agglomeration [29], though of different sizes. As such, the studied spatial scales have gradually shifted from individual cities to urban agglomerations [30,31]. Some scholars have started to examine the impact of urban agglomerations on habitat quality [32], carbon emissions [33], and other social issues.

The methods for characterizing urban expansion and measuring urban form [34] include urban growth typologies [35], standard deviational ellipses [36], concentric rings [37], and landscape indices [38]. Urban growth typologies have been used to portray the morphologies of urban expansion. Standard deviational ellipses have been used to summarize the spatial characteristics of all geographical features, such as dispersion, directional trends, and central trends. Concentric rings can highlight the differences in areas at differing distances from the city center and have usually been used to analyze urban land density [39]. Landscape indices have been used to examine how urban expansion is related to structural changes in land-use practices. Although each method helps to understand one aspect of urban expansion, separately performing these analyses was not comprehensive. In China, some scholars have performed a comparative analysis on the urban expansion pattern of megacities [40,41], while others have analyzed the urban agglomeration in the Yangtze River Delta based on the trend of the "land-population" coordination [42]. However, studies of urban expansion covering the entire YRDR in terms of expansion rate, expansion differentiation, expansion direction, and landscape patterns are still lacking. Moreover, most of the current research focuses on the horizontal comparison and analysis of the urban spatial pattern in different time sections, but the research on the interconnection of and difference in the expansion process between each city is insufficient.

The YRDR has been considered to be the largest regional economy in China [43]. The regional economic collaborative development in the YRDR is critical to enhancing the comprehensive strength of the urban agglomeration [44]. According to the "Outline for the Integrated Development of the Yangtze River Delta Region" released on 13 May 2019 (hereinafter referred to as the Outline), the YRDR has undergone zoning adjustments. Therefore, studies of the spatiotemporal variations in urban expansion occurring as per the Outline can function as references for the government to formulate rational policies and realize regional sustainable development.

We monitored the urban expansion pattern, urban expansion direction, urban expansion spatial autocorrelation, and urban expansion landscape pattern of the cities in the YRDR using land-use data from 1995 to 2018 with a range of methods, namely urban expansion speed index, urban expansion differentiation index, gravity center migration, 
landscape indices, and spatial autocorrelation analysis. The specific objectives are (1) to examine the spatial correlation in the expansion rate of built-up land, (2) to analyze the similarities and differences in the expansion processes of the cities, (3) to identify the direction of the expansion of built-up land by gravity center migration, and (4) to characterize the urban spatiotemporal evolution and landscape patterns.

\section{Materials and Methods}

\subsection{Study Area}

One of the most developed and densely populated industrial regions in China [45], the YRDR, is located $\left(27.20^{\circ} \mathrm{N}-35.33^{\circ} \mathrm{N}, 114.90^{\circ} \mathrm{E}-123.17^{\circ} \mathrm{E}\right)$ in the eastern part of the country and has an area of approximately $357,282 \mathrm{~km}^{2}$, which is approximately $3.7 \%$ of China's whole territory (Figure 1). The YRDR consists of Shanghai, which is the core city, and 40 other cities, of which 13 are in Jiangsu Province, 11 are in Zhejiang Province, and 16 are in Anhui Province. The name and abbreviation of each city are shown in Appendix A Table A1. The YRDR lies in the middle and lower reaches of the Yangtze River and has a long history of agriculture. The YRDR has a variety of geomorphic features, including plains, terraces, hills, and mountains [46]. The topography is low in the northeast and middle, and high in the southwest; meanwhile, the geomorphic types of it belong to the North China Plain, Yangtze River Plain, Jiangnan Hills, and Southeast Hills from the north to the south [47]. In 2018, the total GDP of the YRDR was 21.14 trillion CNY (Chinese yuan), which accounted for $23.48 \%$ of the national GDP, and the total population was 225 million, which accounted for approximately $16.14 \%$ of the entire country's population.

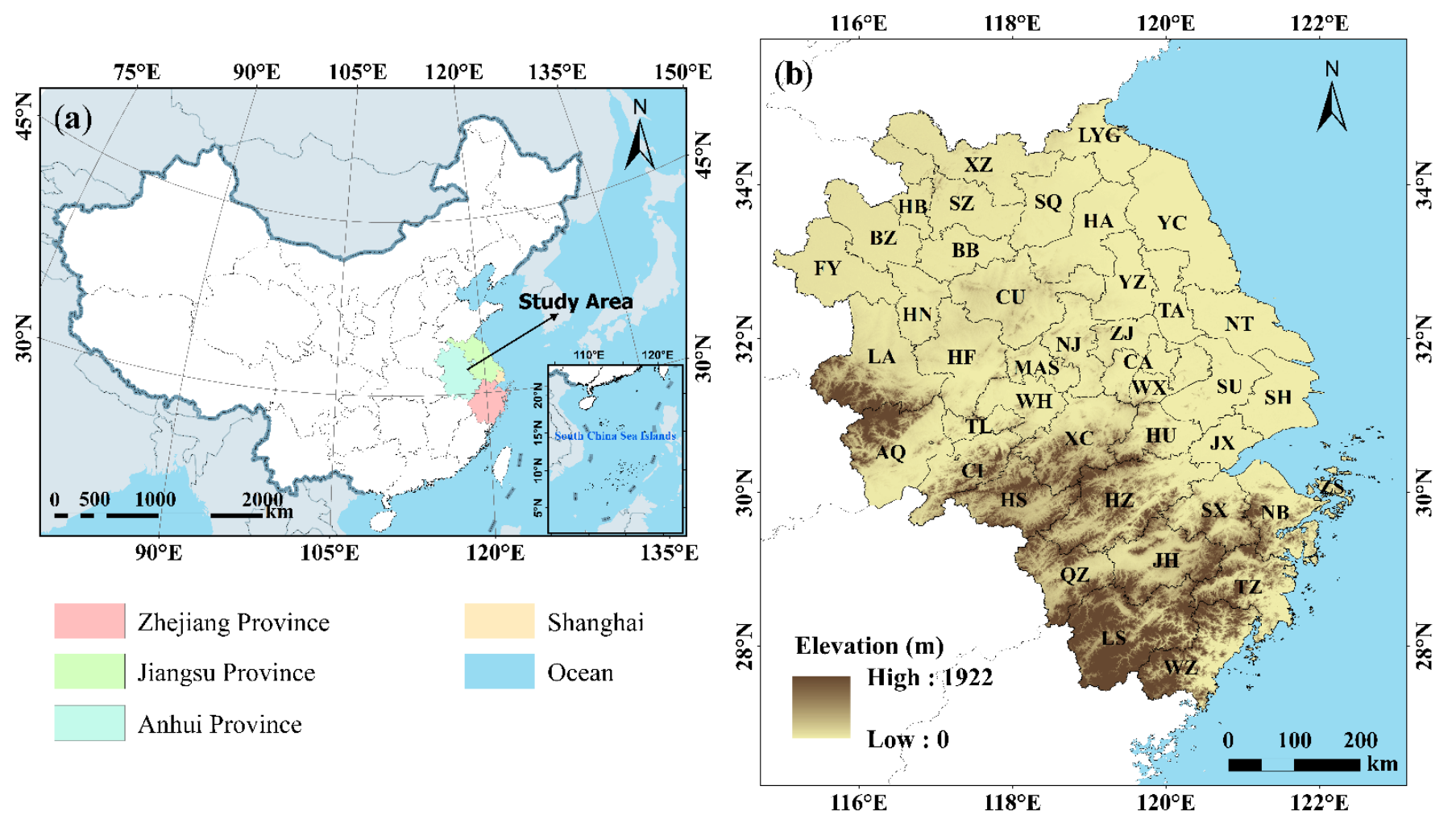

Figure 1. Study area: (a) location of the YRDR in China. (b) the 41 cities of the YRDR. The city names are represented by abbreviations, which are listed in Appendix A Table A1.

\subsection{Data Sources}

This study used land-use data at a $30 \mathrm{~m}$ spatial resolution covering the years 1995, 2000, 2005, 2010, 2015, and 2018, and the YRDR administrative division's vector data. All the data were geo-registered with ArcGIS to the WGS-84 coordinate system. Accessed on 15 January 2021, the land-use and land cover data (LULC) data were part of the 1:100,000 
remote sensing and monitoring of land-use status database of the Resource and Environmental Science Data Center of the Chinese Academy of Sciences (https: / www.resdc.cn/ accessed on 15 January 2021) [45]. This land-use status database has two main characteristics. The first characteristic is high data resolution and continuous data time, which can cover the 6 periods studied. The second characteristic is the high accuracy of the dataset, which conforms to the research requirements of this study $[48,49]$. The land-use types were clipped and reclassified into cropland, forestland, grassland, water bodies, built-up land, and other types of land (sandy land, Gobi, saline land, swamp, bare land, bare rock texture, other unused lands), and vectorized LULC data to extract built-up land (Figure 2).
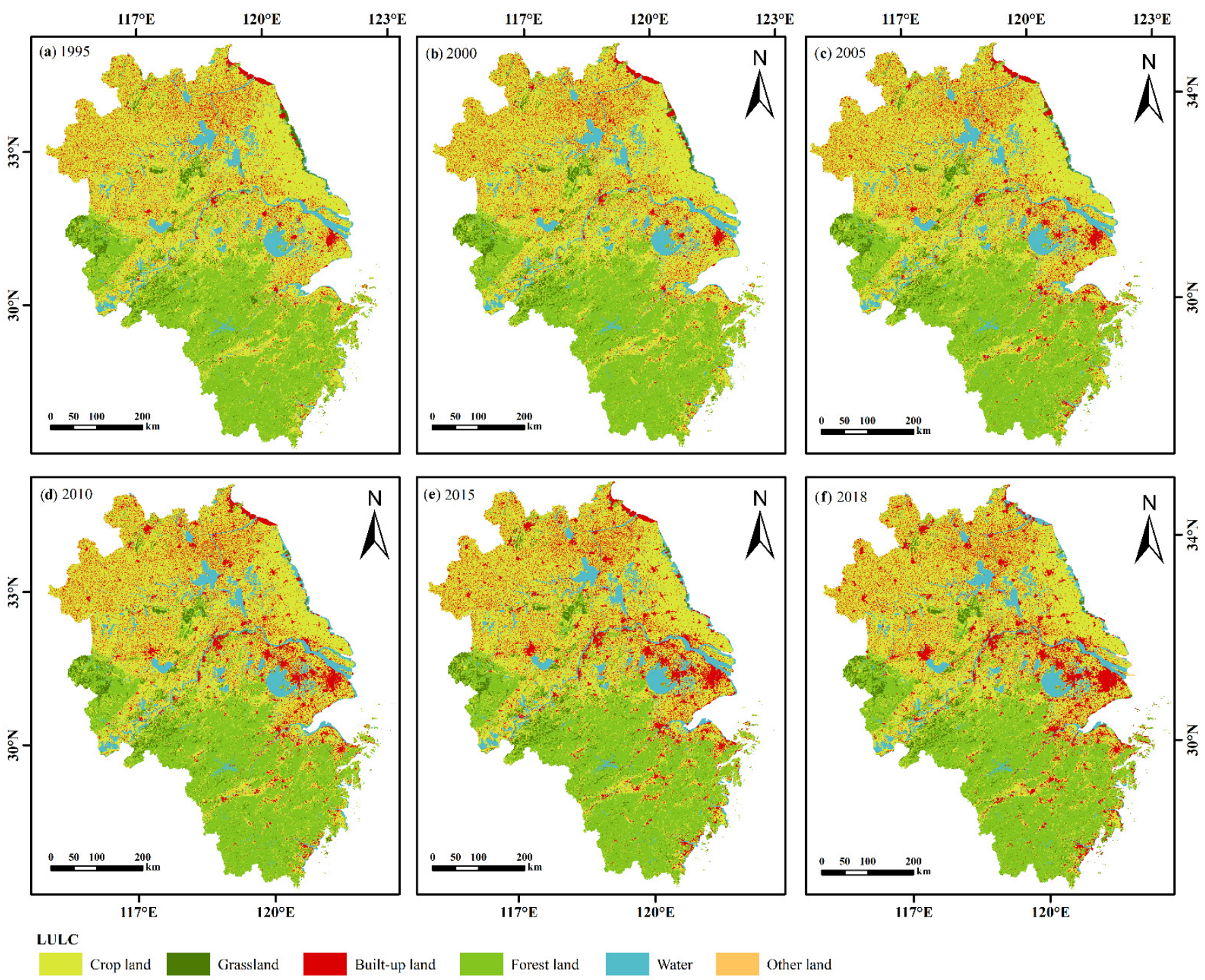

Figure 2. Land-use classification maps of the YRDR in (a) 1995, (b) 2000, (c) 2005, (d) 2010, (e) 2015, and (f) 2018.

\subsection{Methods}

This study describes the urban expansion process of the Yangtze River Delta Region from four aspects: urban expansion pattern analysis, urban expansion direction analysis, urban expansion spatial autocorrelation analysis, and urban expansion landscape analysis. A technical flowchart of this study is presented in Figure 3. 


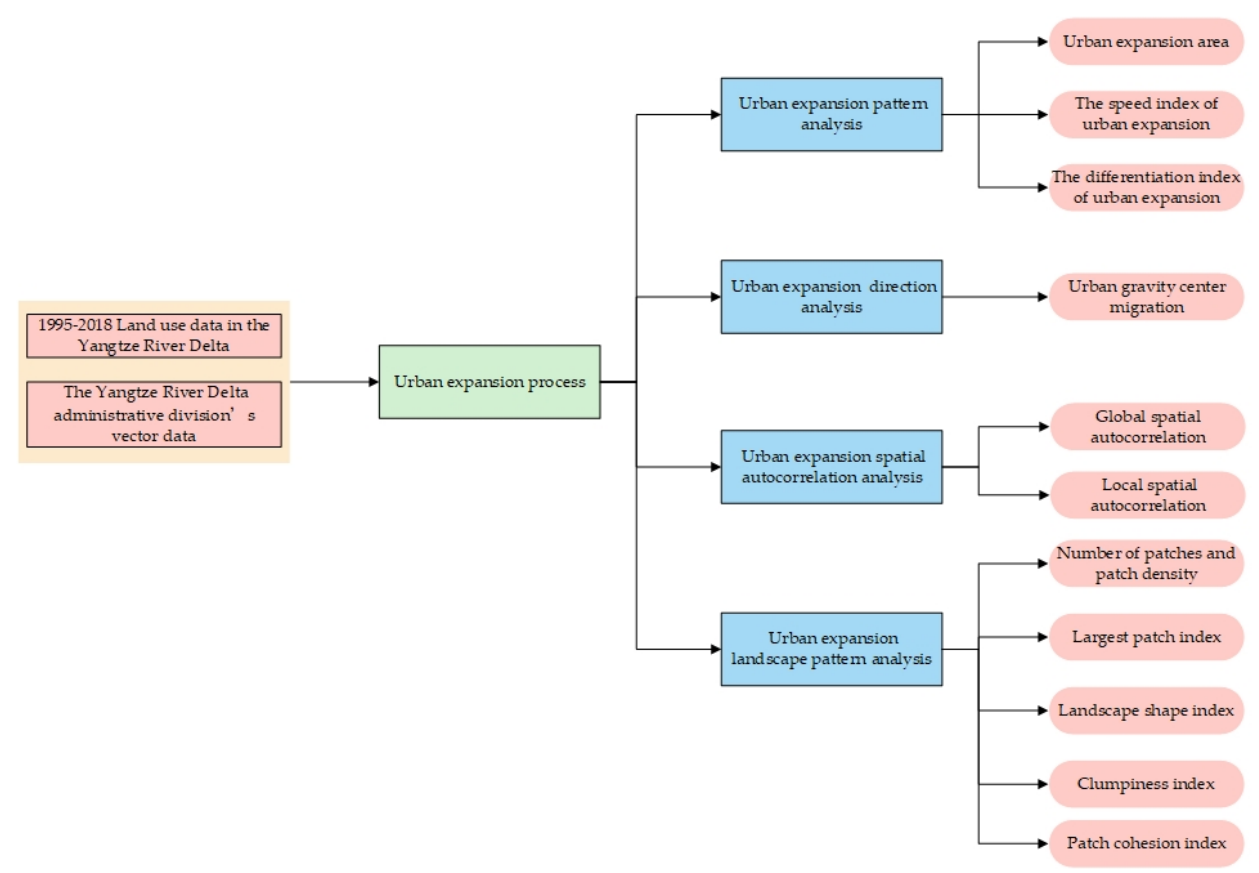

Figure 3. Flowchart of urban expansion in YRDR from 1995 to 2018.

\subsubsection{Speed Index and the Differentiation Index of Urban Expansion}

We calculated two indices: urban expansion speed index (UESI) and differentiation index (UEDI). The former is the rate of the annual changes in built-up land and allows for effective comparisons between the ranges and speeds of changes over different periods in the same spatial unit [50]:

$$
\mathrm{UESI}_{i}=\frac{\mathrm{U}_{i}^{t_{2}}-\mathrm{U}_{i}^{t_{1}}}{\mathrm{U}_{i}^{t_{1}} \times \Delta \mathrm{t}} \times 100 \%
$$

where $\mathrm{U}_{i}^{t_{1}}$ and $\mathrm{U}_{i}^{t_{2}}$ represent the built-up land of spatial unit $i$ at times $t_{1}$ and $t_{2}$ respectively, and $\Delta \mathrm{t}$ indicates the length of time between the times $t_{1}$ and $t_{2}$.

Representing the intensity of changes in land-use types during a specified period in a spatial unit, UEDI is the ratio of the change in the quantity of a land-use type to the quantity of the base period of the land-use type in the whole research area. It allows for comparisons of the speeds of the urban land expansion of different spatial units, as well as for analyses of regional differences and hotspots of urban land expansion [51]:

$$
\mathrm{UEDI}_{i}=\frac{\left|\mathrm{U}_{i}^{t_{2}}-\mathrm{U}_{i}^{t_{1}}\right| \times \mathrm{U}^{t_{1}}}{\left|\mathrm{U}^{t_{2}}-\mathrm{U}^{t_{1}}\right| \times \mathrm{U}_{i}^{t_{1}}}
$$

where $\mathrm{U}_{i}^{t_{1}}$ and $\mathrm{U}_{i}^{t_{2}}$ represent the built-up land of spatial unit $i$ at times $t_{1}$ and $t_{2}$ respectively, while $\mathrm{U}^{t_{1}}$ and $\mathrm{U}^{t_{2}}$ represent the built-up land in the whole research area at times $t_{1}$ and $t_{2}$, respectively [52].

\subsubsection{Gravity Center Migration (GCM)}

The "center of gravity" of a city is a reference point for urban development and expansion that occurs in the same direction as that of migration [53]. GCM is usually used to analyze the dynamic evolution and spatial changes of social, economic, and ecological indicators, such as land-use type, urban evolution, population, and economic development [54]. Comparisons of GCMs in different periods allow for analyses of the directions and trends of changes in urban expansion [55]. In this study, the displacement of a spatial barycenter was used to examine the direction of urban expansion within the YRDUA. The calculation of GCM is based on changes in the coordinates of the gravity center: 


$$
\begin{aligned}
& \mathrm{X}_{t}=\frac{\sum_{i=1}^{n} C_{t i} \times \mathrm{X}_{i}}{\sum_{i=1}^{n} C_{t i}} \\
& \mathrm{Y}_{t}=\frac{\sum_{i=1}^{n} C_{t i} \times \mathrm{Y}_{i}}{\sum_{i=1}^{n} C_{t i}},
\end{aligned}
$$

where $X_{t}$ and $Y_{t}$ are the gravity center's coordinates in year $t, C_{t i}$ is the area (ha) of the $i$-th patch in year $t, X_{i}$ and $Y_{i}$ are the gravity center coordinates of the $i$-th patch, and $n$ is the number of patches.

\subsubsection{Landscape Indices}

Expressed in landscape metrics, landscape patterns include the types, quantities, and spatial distributions of landscape units [56]. Applied extensively to quantify different spatial characteristics of built-up land areas, landscape metrics can reveal the structural changes in land-use practices [57]. Therefore, comparing the landscape metrics in different periods would effectively reflect the manner and process of urban expansion. We selected six landscape metrics (Table 1) from class-level metrics [58]. We analyzed and compared the effects of urban expansion in the YRDR and calculated the landscape metrics with FRAGSTATS 4.2 software (http:/ / www.umass.edu/landeco/research/fragstats/fragstats. html accessed on 17 May 2021).

Table 1. Landscape indices used in this study.

\begin{tabular}{cccc}
\hline Metrics & Acronym & Units & Description \\
\hline Largest Patch Index [58] & LPI & Percent & The percentage of the landscape comprised of the largest patch. \\
Number of Patches [59] & NP & None & The number of patches of landscape classes. \\
Patch Density [60] & PD & Number per $\mathrm{km}^{2}$ & The extent of subdivisions in or the fragmentation of the patch type. \\
Clumpiness Index [61] & CLUMPY & Percent & The aggregation degree of the landscape. \\
Landscape Shape Index [62] & LSI & None & The complexity of urban growth. \\
Patch cohesion index [63] & COHESION & None & The physical connectedness of the corresponding patch type. \\
\hline
\end{tabular}

\subsubsection{Spatial Autocorrelation}

To analyze the characteristics of the spatial distribution aggregation and differentiation of the regional urban built-up land expansion speed index (Appendix A Table A2), spatial autocorrelation in spatial statistics was used for two different approaches to scale spatial pattern analysis: global and local spatial autocorrelation [64]. Spatial autocorrelation reflects the overall distribution characteristics, such as the average degree of association, spatial distribution patterns, and significance, of attribute values in space [65]. Moran's I range between -1 and 1 for global spatial autocorrelation is used to measure aggregate, discrete, and random regional attribute values quantitatively. Values of less than, equal to, and greater than 0 signify a negative correlation, an independent random distribution, and a positive correlation, respectively [66]. Global spatial autocorrelation can only examine the overall spatial autocorrelation of the study area but cannot determine the agglomeration or dispersion effects in a local area [43]. Therefore, Moran's I for local spatial autocorrelation analysis was used. It and its local variant $I_{i}$ are respectively defined as:

$$
\mathrm{I}=\frac{n}{\sum_{i=1}^{n} \sum_{j=1}^{n} w_{i j}} \times \frac{\sum_{i=1}^{n} \sum_{j=1}^{n} w_{i j}\left(x_{i}-\bar{x}\right)\left(x_{j}-\bar{x}\right)}{\sum_{j=1}^{n}\left(x_{i}-\bar{x}\right)^{2}}
$$

where $n$ is the total number of units, $x_{i}$ and $x_{j}$ are the values of points $i$ and $j$ respectively, $\bar{x}$ is the average value of all units, and $w_{i j}$ is the spatial weight matrix of spatial units $i$ and $j$ (when unit $i$ and unit $j$ are topologically adjacent with a common edge, $w_{i j}=1$, otherwise $\left.w_{i j}=0\right)[66]$.

$$
\mathrm{I}_{i}=\frac{\left(x_{i}-\bar{x}\right)}{\sum_{i=1}^{n}\left(x_{i}-\bar{x}\right)} \sum_{j=1}^{n} w_{i j}\left(x_{i}-\bar{x}\right),
$$


The meaning of the letters in Formula (6) is the same as of those in Formula (5).

A cluster map of the local indicators of spatial association (LISA) can show four different patterns: High-High (HH), Low-Low (LL), High-Low (HL), and Low-High (LH) [63]. A spatial unit that is an HH or LL agglomeration zone indicates that its $\mathrm{UESI}_{i}$ and those of the surrounding cities around are high or low, respectively. An HL agglomeration zone indicates that its $\mathrm{UESI}_{i}$ is high, but those of the surrounding cities are low. An LH agglomeration zone indicates that its $\mathrm{UESI}_{i}$ is low, but those of the surrounding cities are high. A scatter plot of Moran's I would also have four quadrants that indicate its values for all geographic units.

\section{Results}

\subsection{Spatiotemporal Patterns of Urban Expansion at the Regional Scale}

Urban land use in the YRDR continued to experience rapid urban expansion in the late 1990s (Figure 4). The urban area increased monotonically by $18,413.180 \mathrm{~km}^{2}$ and the percentage of the entire urban agglomeration nearly doubled from $8.3 \%$ to $13.5 \%$. The expansion speed reached its peak in 2005-2010. The average annual increase was $800.57 \mathrm{~km}^{2}$, respectively. Over the study period, the expansion speed exhibited a "peak-topeak" trend and the YRDR land area increased steadily.
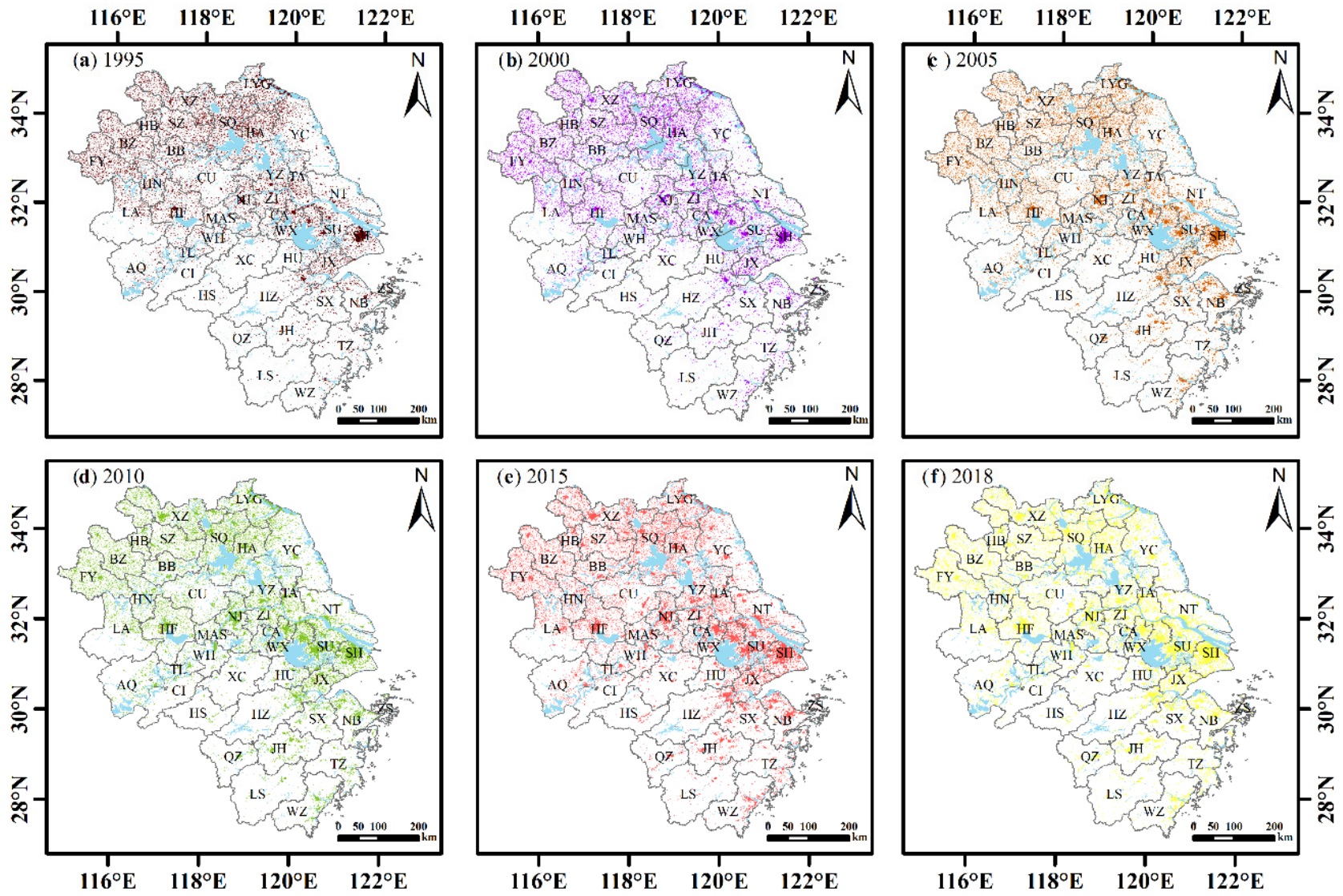

Urban Expansion

Built-up in 1995

Built-up in 2000

Built-up in 2015

Built-up in 2018

Built-up in 2005

Built-up in 2010

Figure 4. Urban land expansion of the YRDR in (a) 1995, (b) 2000, (c)

Non Built-up Area

\subsection{Spatiotemporal Patterns of Urban Expansion at the City Scale}

The magnitude of urban expansion varied greatly by city. The values for the UESI are shown in Appendix A Table A2. To reveal the expansion of the interconnections between the cities, we used global and local spatial autocorrelation to explore the correlations 
of the index. Moran scatterplots for these data are presented in Figure 5. Moran's I of the UESIs are $0.2207,0.8509,0.4375,0.3903,0.1982$, and 0.8614 in 1995-2000, 2000-2005, 2005-2010, 2010-2015, 2015-2018, and 1995-2018, respectively. All the results demonstrate significant positive correlations with neighboring regions. Throughout this period, the spatial correlation showed a "peak-trough-peak" trend. The Moran scatterplot has four quadrants. The HH quadrant shows small spatial differences between the cities, thus indicating spatial diffusion effects, whereas the LH quadrant indicates spatial transition characteristics. The LL quadrant indicates spatial aggregation effects in a slowly growing region. The HL quadrant shows that the attribute levels of the region itself are high, but those of the surrounding regions are low, thus indicating spatial polarization characteristics. The quadrant distribution of each city in the Moran scatterplot is shown in Figure 6.

A LISA map of the UESI for each city at the 0.05 significance level in different periods is shown in Figure 7. The "hot" spots and "cold" spots of urban expansion in the YRDR have continued to move spatially. The cities, LS and HZ, were "hot" cities with high stability during 1995-2018. The gradual shift of "hot" cities from the southern to the middle part of the urban agglomeration is indicative of urban expansion, and the intensity of urban land use is also increasing. The "cold" cities are mainly located in Anhui and northern Jiangsu Provinces.
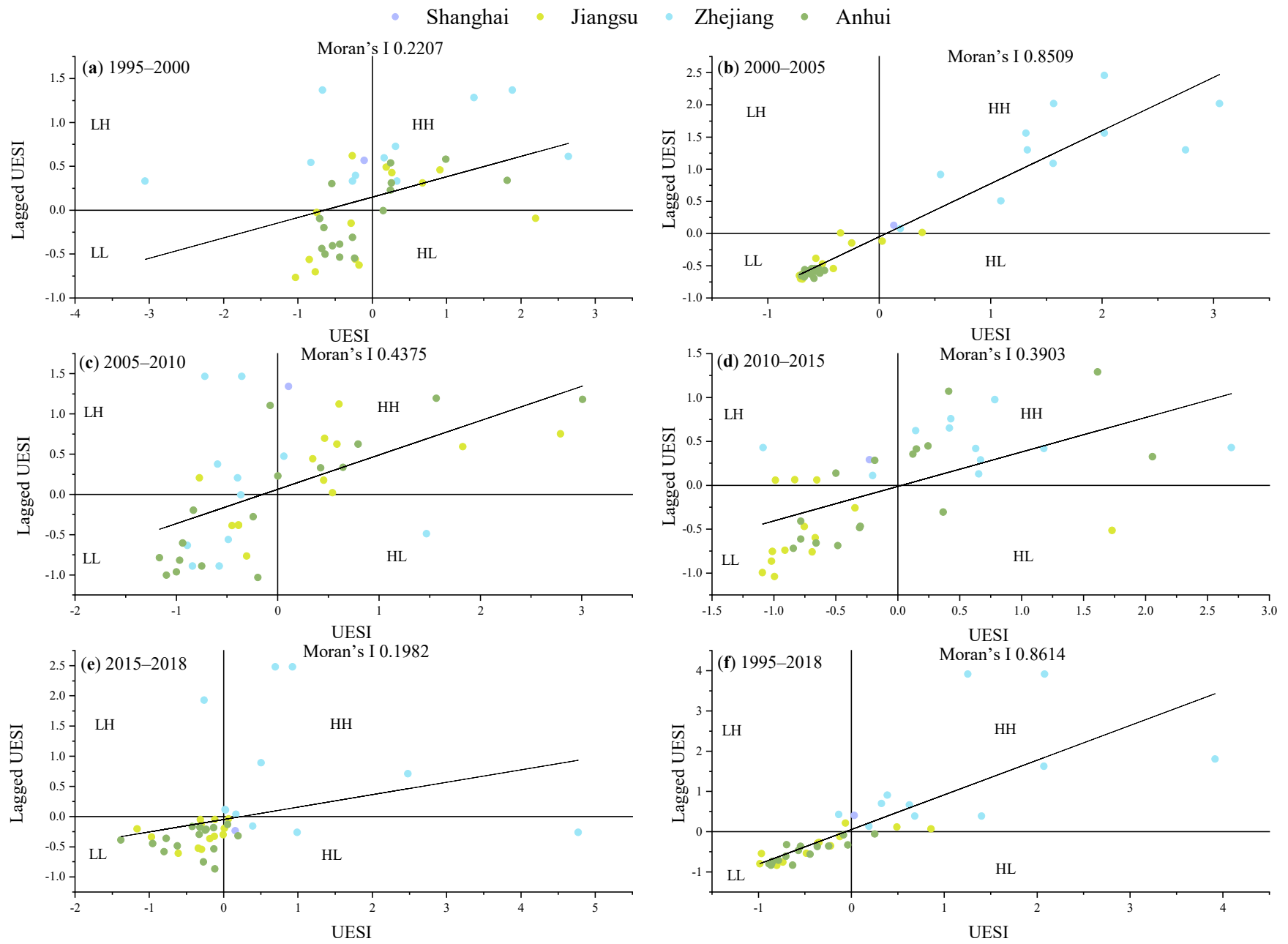

Figure 5. Moran scatterplots of UESIs for the YRDR in different periods: (a) 1995-2000, (b) 2000-2005, (c) 2005-2010, (d) 2010-2015, (e) 2015-2018, and (f) 1995-2018. 

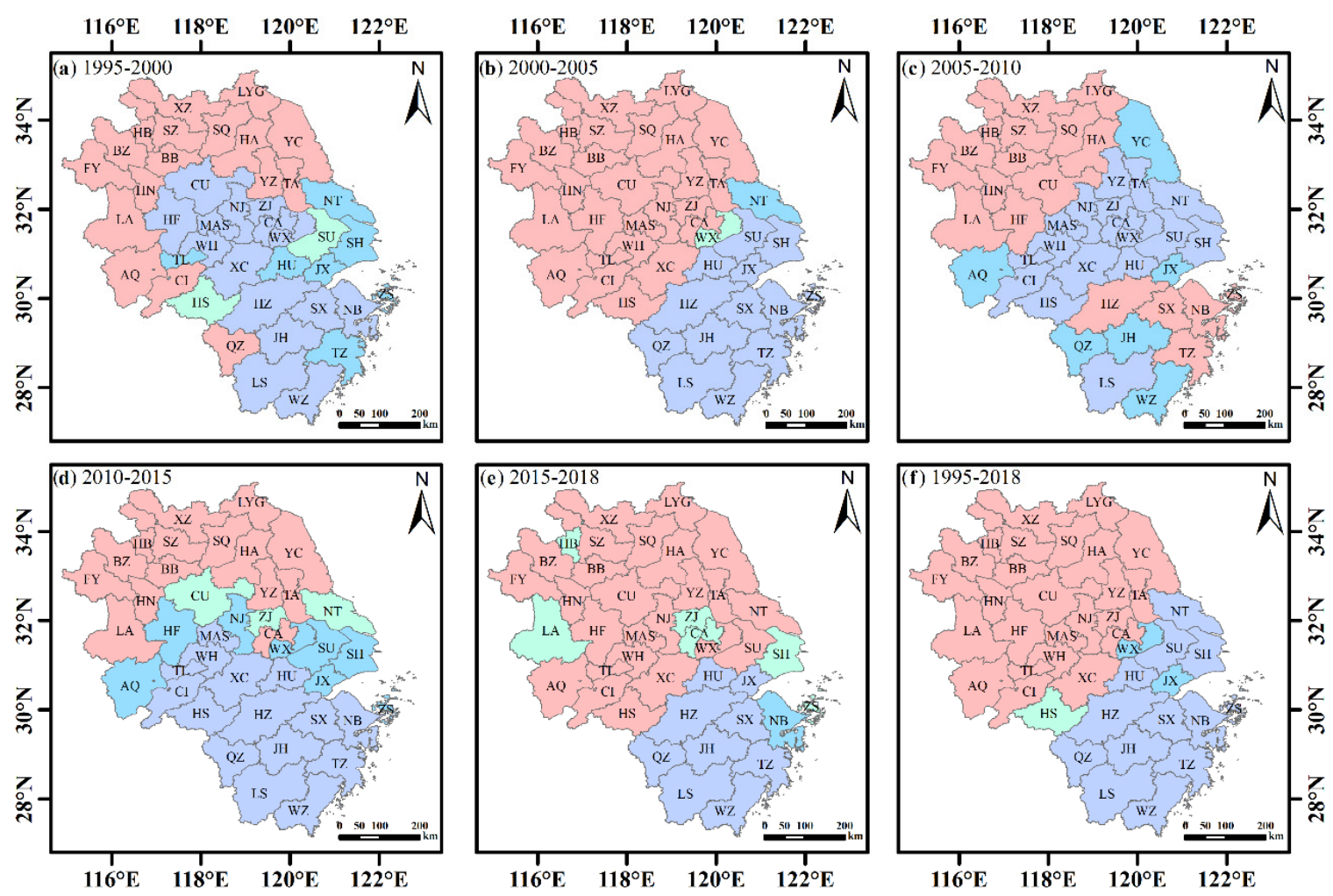

Legend

$\square$ High-High quadrant $\square$ Low-High quadrant $\square$ High-Low quadrant $\square$ Low-Low quadrant

Figure 6. Moran scatterplots of urban distributions in the YRDR: (a) 1995-2000, (b) 2000-2005, (c) 2005-2010, (d) 2010-2015, (e) 2015-2018, and (f) 1995-2018.
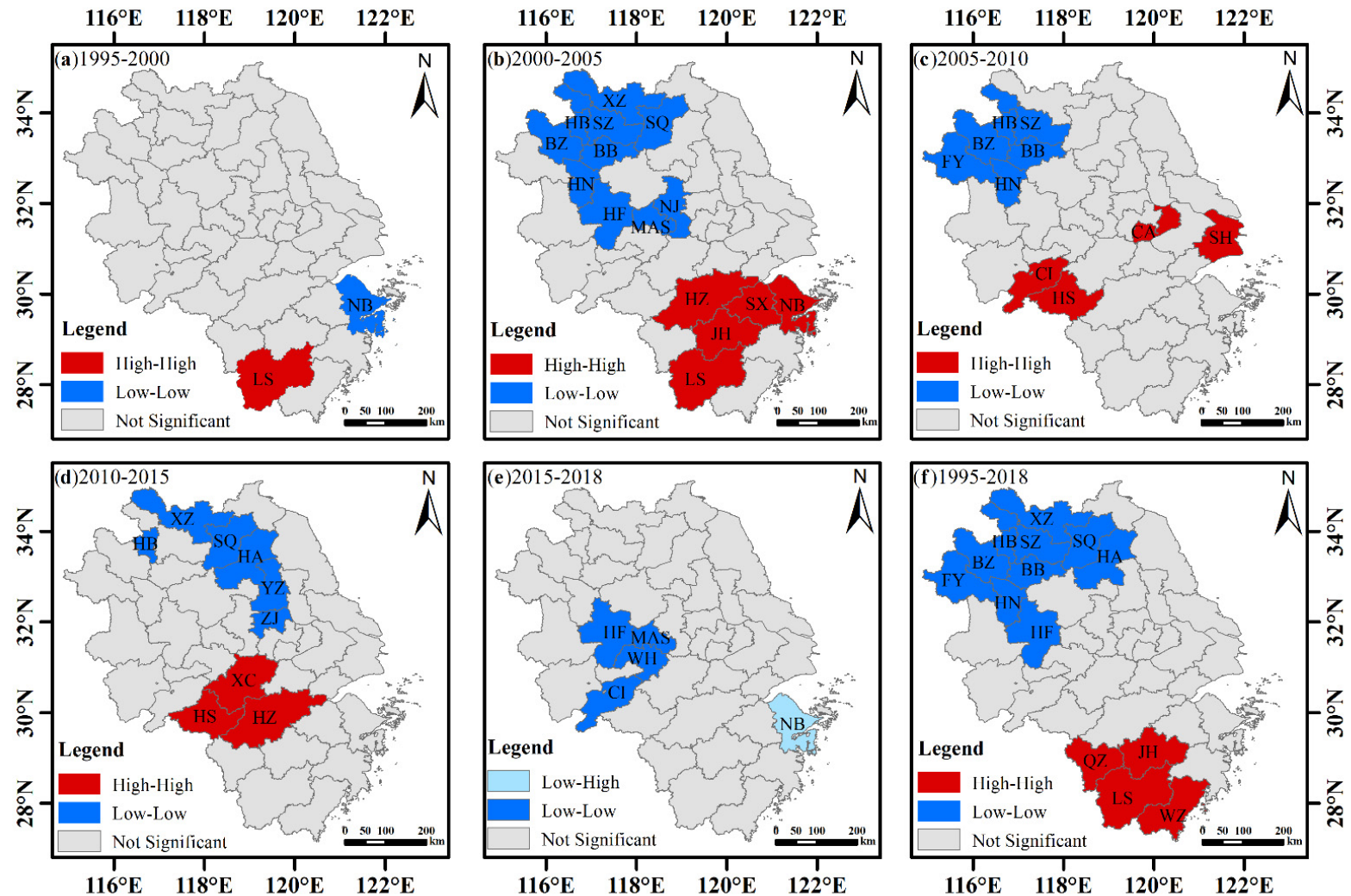

Figure 7. Local indicators of spatial association (LISA) cluster maps of UESI for each city in different periods: (a) 1995-2000, (b) 2000-2005, (c) 2005-2010, (d) 2010-2015, (e) 2015-2018, and (f) 1995-2018. 


\subsection{Differentiation Characteristic of the Urban Expansion}

To compare the differences in the expansion of different cities, we calculated the UEDI of each city at various stages and used the natural breakpoint classification method to classify the status of development into five levels: slow-speed, low-speed, medium-speed, rapid-speed, and high-speed development. The high-speed expansion area gradually shifts from the middle of the YRDR to the south, mainly in Zhejiang and southern Jiangsu Provinces. The urban land expansion in the northwest and northeast of the region shows a slow trend. Most cities in Anhui Province and northern Jiangsu Province have slowor low-speed development. Their UEDIs show obvious development gaps between the cities (Figure 8).
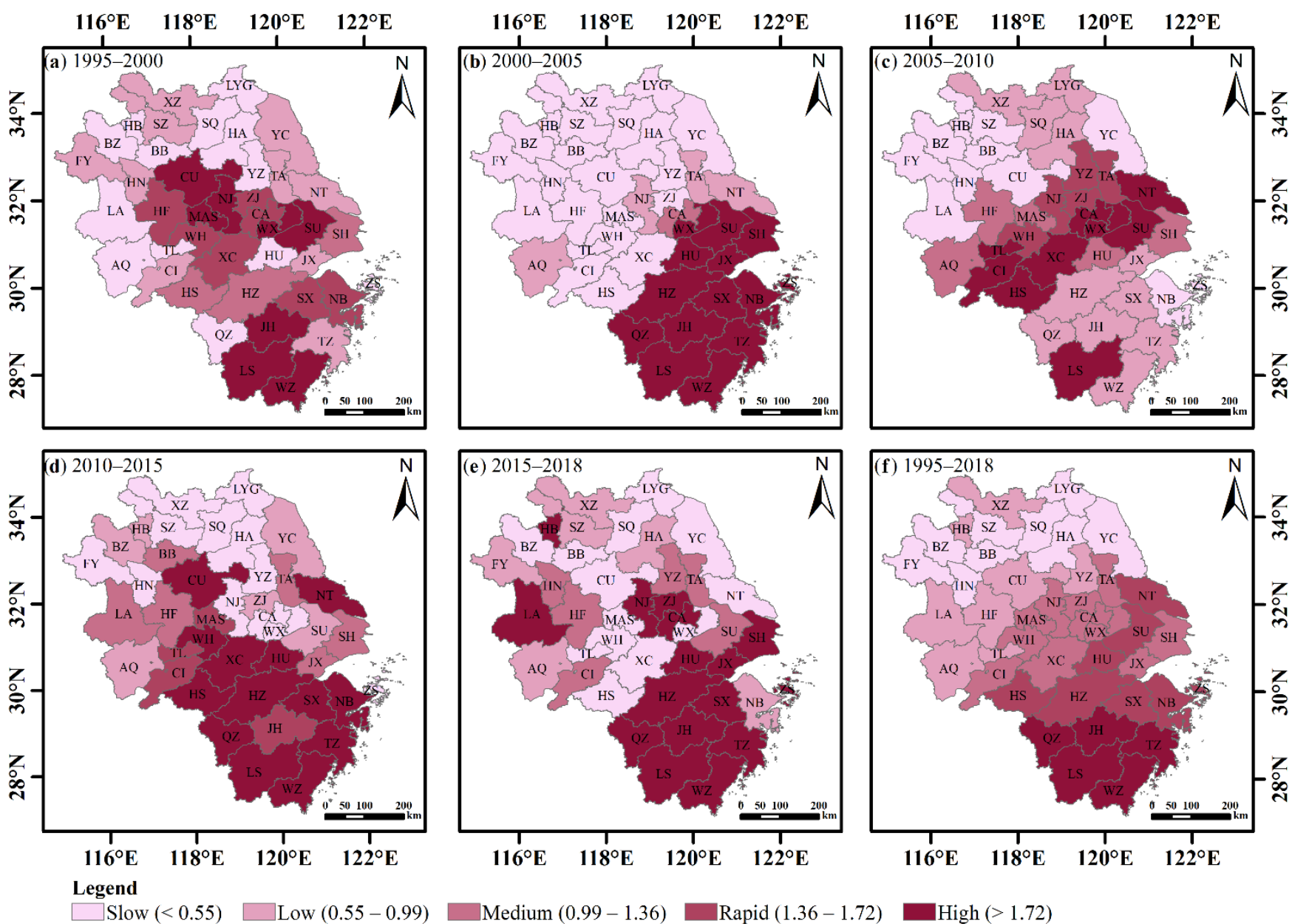

Figure 8. The spatial characteristics of the UEDIs in the YRDR: (a) 1995-2000, (b) 2000-2005, (c) 2005-2010, (d) 2010-2015, (e) 2015-2018, and (f) 1995-2018.

From 1995 to 2000, the cities with rapid urban expansion were located in the central and southern parts of the urban agglomeration, roughly presenting an S-shaped area with SU as the starting point and WZ as the ending point. SU, WX, MAS, NJ, CU, JH, LS, and WZ had the fastest expansion. From 2000 to 2005, with SH-SU-WX-HU-HZ-QZ as the dividing line, the YRDR was divided into one part with medium-, low-, and slow-speed development and another part with rapid-speed development. All five types of expansion levels showed obvious agglomeration characteristics. From 2005 to 2010, the high- and rapid-speed development areas, except for LS, were concentrated in the middle of the urban agglomeration. From 2010 to 2015, the expansion of NT, HS, XC, and cities in the provinces of Zhejiang maintained a steady trend, whereas the expansion of $\mathrm{CU}, \mathrm{WH}$, and $\mathrm{HU}$ in Anhui Province began to accelerate. NT, WH, XC, HS, and TZ had the fastest 
expansion. From 2015 to 2018, the levels of slow-, low-, and medium-speed expansion were relatively scattered, and cities in the province of Zhejiang maintained a high-speed development. However, only HU and LA in Anhui province, NJ, ZJ, and CA in Jiangsu province, and $\mathrm{SH}$ are in high-speed development.

The overall difference pattern of expansion in the YRDR during the entire study period of 1995-2018 is clearly defined, with slow-, low-, and medium-speed development in the north, and rapid- and high-speed development in the south, with NT-SU-HU-HZ-HS as the dividing line. The areas along the coastal development zone developed faster.

\subsection{Migration of the Gravity Center of Urban Built-Up Land}

At the city scale, the gravity centers of the YRDR were located in CU $\left(118.146^{\circ} \mathrm{E}-\right.$ $118.229^{\circ} \mathrm{E}, 32.287^{\circ} \mathrm{N}-32.316^{\circ} \mathrm{N}$ ) during the 23 years of the study period (Table 2). Figure 9 illustrates the built-up land gravity center for each district at six different times. Although the gravity centers of the built-up land shifted southeast, southwest, and northwest, the overall focus has been southwest because of the rapid development of built-up land in the southern part, especially in Zhejiang Province, of the urban agglomeration. Before 2005, the GCM distances were smaller and the migration directions were southeast. The maximum GCM distance in 2005-2010 reached $7626.807 \mathrm{~m}$ and the migration directions changed from southeast to southwest, indicating that the gravity centers of built-up land growth at this time had shifted to the southwest of the urban agglomeration. The growth was relatively rapid, with the annual offset distance reaching its peak of $1525.361 \mathrm{~m} /$ year. In 2015, the centers of built-up land growth shifted to the northwest of the urban agglomeration with an annual offset distance of $564.079 \mathrm{~m} /$ year. The focus of urban growth in 2018 returned to the southeast of the urban agglomeration and has maintained a high expansion rate. At the city scale, the direction of the GCMs of 15 cities (AQ, CA, CI, HZ, JH, LS, MAS, QZ, SX, TL, WZ, WX, WH, XC, and ZJ) was southwest, which was consistent with the GCM of the entire YRDR. The direction of the GCMs of seven cities (BB, FY, HS, LYG, LA, NT, and $\mathrm{SU})$ was northwest and of six cities (BZ, NJ, SH, SQ, SZ, and YC) was southeast, whereas five cities (HF, JX, TZ, YZ, ZS. HU, HA, HB, HN, and NB) in the northeast showed obvious expansion toward the south. Only $\mathrm{CU}, \mathrm{TA}$, and $\mathrm{XZ}$ showed different expansion directions toward the west, north, and east, respectively.

\subsection{Landscape Patterns of Urban Built-Up Land}

The landscape pattern indices of each city in the YRDR during 1995-2018 are shown in Figure 10. The PD and NP of most urban built-up areas experienced negative changes. The LSI of each city shows a decreasing trend, indicating that the landscape shape of the built-up land tended to become simplified. Nevertheless, the LPI of the built-up land of each city revealed that the largest patch areas, especially in SH and SU, of built-up land had increased. However, CLUMPY and COHESION showed similar trends during this period, indicating an aggregation or a clumping of urban patches.

Table 2. Changes in built-up land gravity centers from 1995 to 2018.

\begin{tabular}{ccccccc}
\hline & Year & Longitude $\left(^{\circ}\right)$ & Latitude $\left(^{\circ}\right)$ & Direction $\left(^{\circ}\right)$ & Distance $(\mathbf{m})$ & Rate $(\mathbf{m} /$ year $)$ \\
\hline & 1995 & 118.214 & 32.316 & & & \\
& 2000 & 118.226 & 32.313 & Southeast 13.279 & 1227.763 & 245.553 \\
Yangtze River & 2005 & 118.229 & 32.311 & Southeast 52.816 & 377.295 & 75.459 \\
Delta & 2010 & 118.151 & 32.290 & Southwest 18.007 & 7626.807 & 1525.361 \\
& 2015 & 118.123 & 32.298 & Northwest 17.246 & 2820.397 & 564.079 \\
& 2018 & 118.146 & 32.287 & Southwest 27.985 & 2489.969 & 829.990 \\
\hline
\end{tabular}




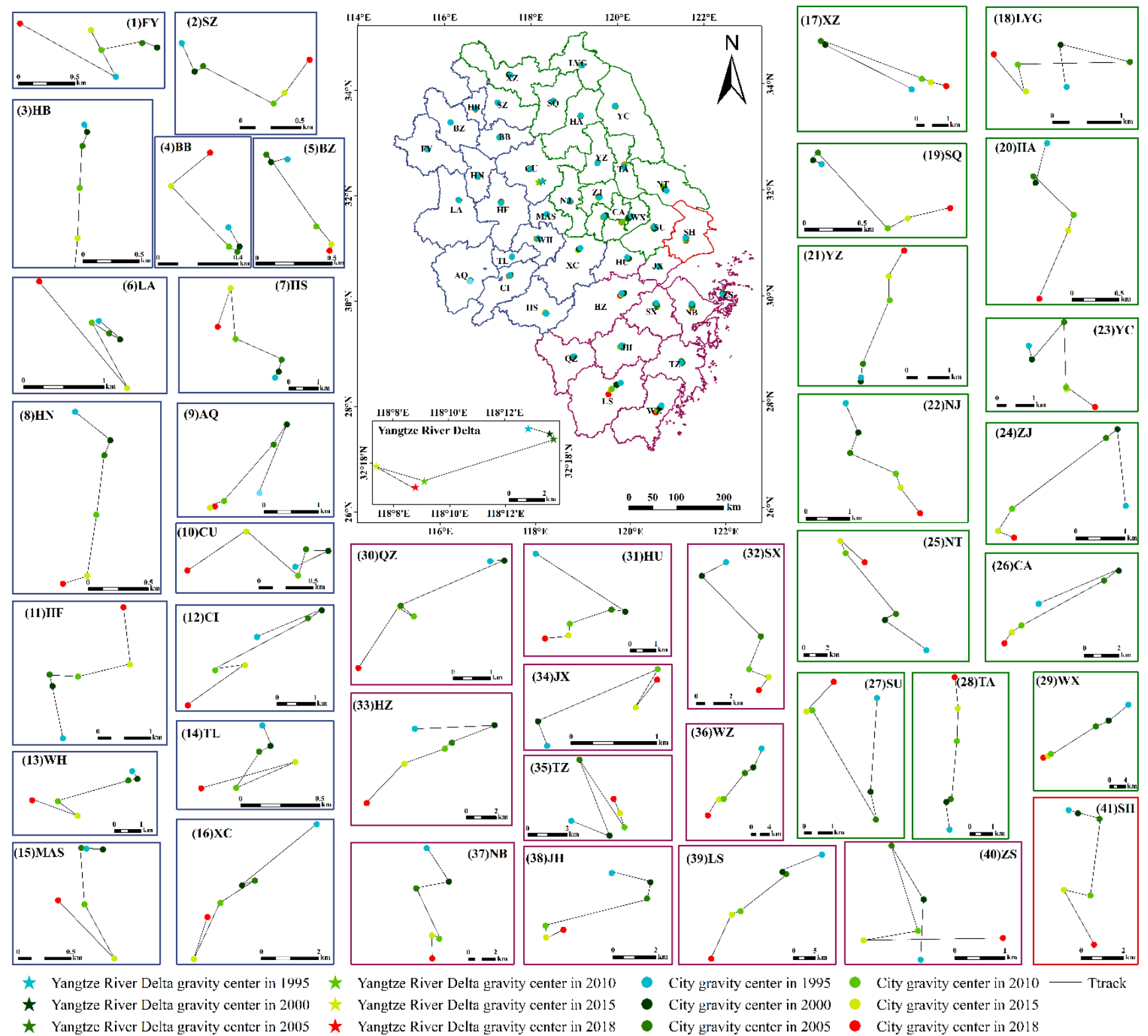

Figure 9. Built-up land gravity centers for the entire study area and each city from 1995 to 2018.

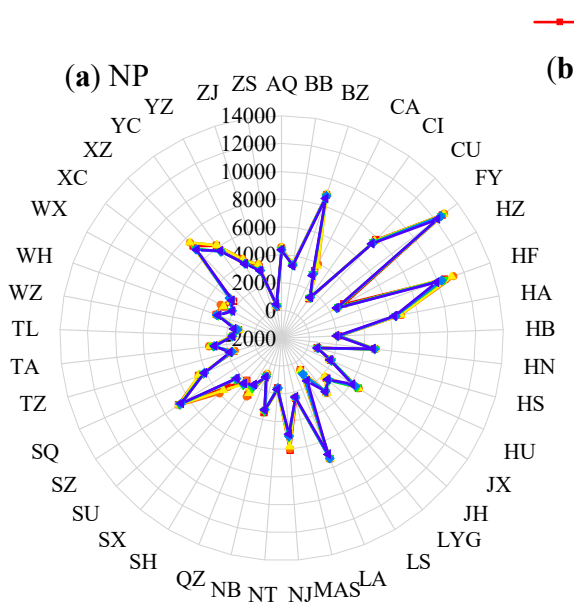

$\rightarrow-1995 \longrightarrow 2000 \longrightarrow 2005 \longrightarrow 2010 \longrightarrow-2015 \longrightarrow 2018$

(b) PD (number $\left./ \mathrm{km}^{2}\right)$

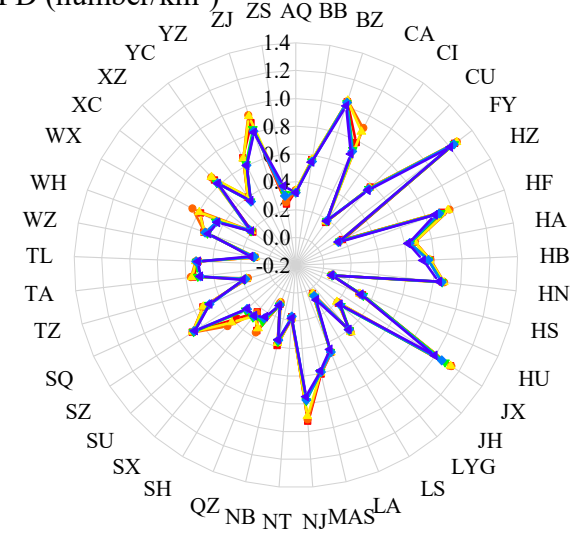

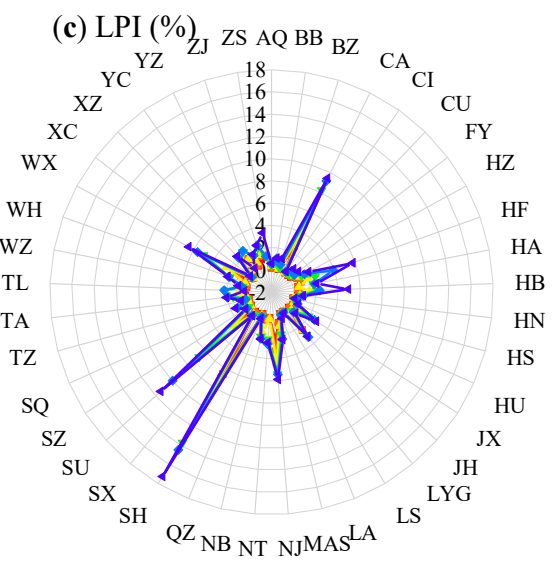

Figure 10. Cont. 

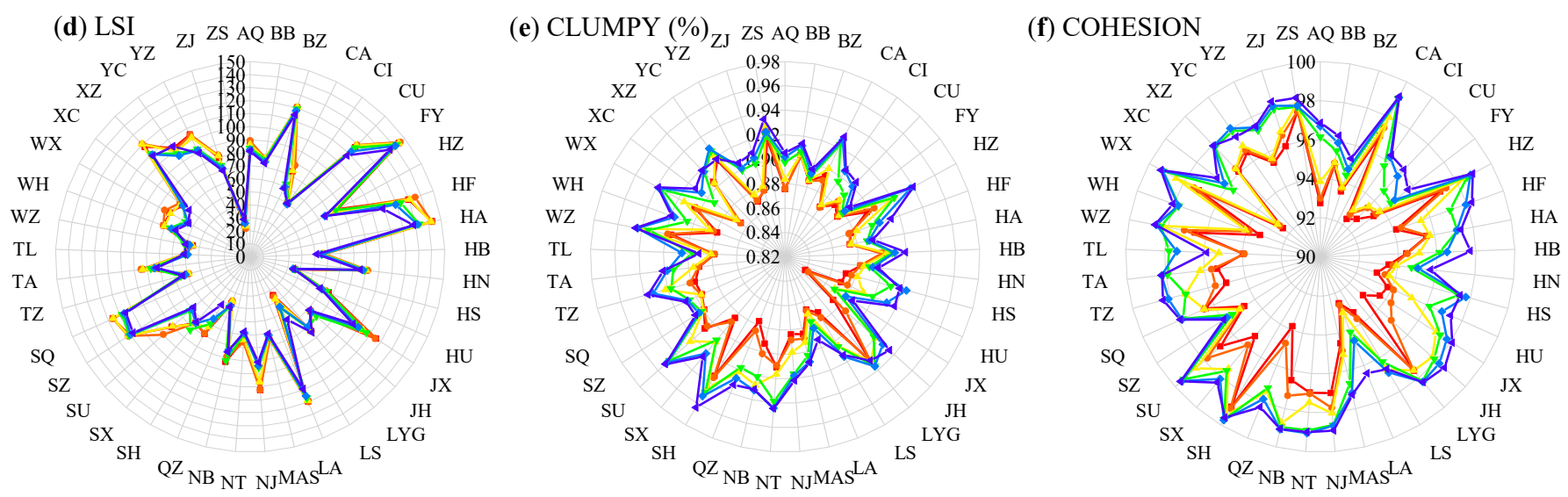

Figure 10. Landscape indices of built-up land from 1995 to 2018: (a) NP, (b) PD, (c) LPI, (d) LSI, (e) CLUMPY, and (f) COHESION.

\section{Discussion}

Using the land-use data of six periods (1995, 2000, 2005, 2010, 2015, and 2018), we analyzed the spatiotemporal evolution characteristics of the past 23 years of the urban agglomeration in the Yangtze River Delta Region (YRDR) and examined spatial expansion intensity, expansion differentiation, GCMs, landscape patterns, and spatial autocorrelations of urban land use.

\subsection{Expansion Rates and Differences}

Having examined the Beijing-Tianjin-Hebei urban agglomeration, this study found that the expansion rate of Beijing during 1995-2000 was 2\% [67], whereas the expansion rates of eight cities in the YRDR had been higher: CU (2.6\%), JH (4.9\%), LS (3.1\%), MAS $(3.7 \%), \mathrm{NJ}(2.8 \%)$, WZ (3.8\%), and WH (2.2\%). The highest expansion rate in the Pearl River Delta urban group was GZ (14.1\%) during 2000-2005 [19]. The expansion rate of SZ was 2.6\% during 2005-2010 [19]. During 2000-2005, 5 cities in the YRDR had higher expansion rates than did GZ, and during 2005-2010, 29 cities in the YRDR had higher expansion rates than did SZ. The expansion rates of SH (1.8\%), NB (3.04\%), and HZ (3.7\%) were lower than that of Beijing (5.1\%) [52], but 17 cities had expansion rates higher than that of GZ (1.9\%) [19] during 2010-2015. These comparisons show that the expansion intensities of the cities in the YRDR were higher than in the Pearl River Delta but similar to those in the Beijing-Tianjin-Hebei Delta.

The expansion rates between the cities have obvious spatial autocorrelations. Most cities in the YRDR are located in the HH and LL clusters, which indicate homogeneous expansion rates and positive spatial autocorrelations. The HL and LH aggregation zones indicate heterogeneous expansion rates and negative spatial autocorrelations. The LISA cluster map revealed the morphological characteristics of "small agglomeration and large dispersion" and the overall low degree of agglomeration among the cities. In terms of time, the YRDR had significant spatial hotspots during the four stages of urban expansion. Consistent with the findings of [67], the expansion hotspots are dynamically shifting and show a volatility expansion with Shanghai as the core and the expansion hotspots distributed in Zhejiang, Jiangsu, and Anhui Provinces.

In terms of the expansion difference index, the small- and medium-sized cities have faster growth rates, whereas the larger cities have lower growth rates [68]. The high-speed expansion area is gradually shifting from the middle of the YRDR to the south, mainly to Zhejiang and southern Jiangsu Provinces. The built-up land expansion in the northwest and northeast of the region shows a slow trend. Most cities in Anhui and northern Jiangsu Provinces exhibit slow- or low-speed development. The main reasons for the temporal and spatial differences in built-up land expansion in the YRDR are policy factors such 
as administrative divisions, economic levels, industrial structures, and other social and economic factors, which have guided the expansion speeds and directions of built-up land.

\subsection{Expansion Directions}

The characteristics of the GCMs indicate that there are differences in the development of the cities in the YRDR, but they do not provide information concerning controlling factors. The different levels of development have driven the transformations of the statuses of the cities in the entire YRDR. Eventually, the gravity center of the urban agglomeration moved to the southwest, where the natural and locational conditions are superior while the economic and social development is more rapid. The specific functions of each city are gradually highlighted and the interactions between cities are strengthened. On the whole, the center of gravity of the YRDR will continue to move toward the southwest. An in-depth analysis of the locational and movement trends of the center of gravity would have an important and theoretical guiding significance, as well as practical operational implications for future strategic plans that would continue the rapid development of the YRDR.

\subsection{Landscape Patterns}

Except for ZS, LS, SX, TZ, WZ, CI, JH, XC, QZ, and NT, the PDs of the cities in the YRDR decreased during 1995-2018, indicating decreasing landscape heterogeneity of built-up land. NP also shows a decreasing trend, which indicates that the number of landscapes is decreasing because the plaques between these urban built-up areas are gradually being filled, gathered, and merged into one plaque, thus decreasing the overall number of plaques but increasing the area of built-up land [69]. The landscape patterns of built-up land have shown lower degrees of fragmentation as the cities developed. This finding also appears in $[70,71]$ but contradicts the characteristics of the landscape patterns in the Pearl River Delta [72]. Except for LS, WZ, ZS, TZ, QZ, LYG, YC, TL, and CI, the LSIs of the cities in the YRDR decreased to reveal that the shape of the landscape was gradually becoming simpler. This situation may be the result of the cities in the YRDR being less disturbed by the external environment and their internal stability remaining relatively strong. COHESION increased from 1995 to 2018, implying that the degrees of reunification, extension, and connectivity of built-up land are gradually improving. The gradual increase in land use during this period in the YRDR has gradually connected the cities to form more concentrated and compact urban patches. The changes in CLUMPY imply slight changes in the aggregated distribution of built-up land. The values of CLUMPY for SH, SU, WZ, HZ and NT have maintained high levels, indicating that high urban land intensification has mainly been due to terrain and economic factors. The various cities are relatively independent. The LPI can be regarded as a contiguous area in the primary urban area of a city and shows that the expansion of urban built-up areas is manifested in a coordinated expansion model centered on the main urban area and surrounding districts. Such an expansion is conducive to the gradual transformations of the cities from a single-center development model to a multi-center coordinated development model.

\subsection{Innovations and Limitations}

Current research on long-term serial urban expansion covering entire urban agglomerations is relatively lacking when compared to research on individual cities. Incorporating the urban agglomeration scale, this study combined different methods, such as urban speed indices and differentiation indices of urban expansion, GCM, landscape indices, and spatial autocorrelations, to fully quantify the expansion of urban agglomerations. However, the driving force that influences the expansion of urban agglomerations should be explored further. The expansion mode of different core areas within a city, the similarities and differences of the expansion of landscape patterns, and the impact of anthropogenic modifications on the pristine environment are worthy of further study. 


\section{Conclusions}

Using the land-use data of six periods, we summarized the spatiotemporal evolution patterns of built-up land with urban speed indices and the differentiation indices of urban expansion, gravity center migration, landscape indices, and spatial autocorrelations. The key findings and main conclusions are as follows:

- The built-up land area of the Yangtze River Delta Region continues to increase with an expansion of nearly double in size, from $29,600.715$ to $48,013.895 \mathrm{~km}^{2}$. The expansion speed of the Yangtze River Delta Region shows a significant spatial agglomeration trend. The degree of agglomeration first increases, then decreases with time. The high-speed expansion areas are mainly concentrated in the middle and south of the Yangtze River Delta Region. This is mostly affected by the differences in the levels of development of the cities in the Yangtze River Delta Region.

- There are significant differences in the expansion direction of built-up land in the Yangtze River Delta Region, as each city has a different impact on the entire area. Eventually, the center of gravity is moving toward the faster-developing southwestern region. An in-depth analysis of the locational and movement trends of the center of gravity would have an important and theoretical guiding significance, as well as practical operational implications for future strategic plans that would continue the rapid development of the Yangtze River Delta Region.

- During 1995-2018, the spatial structure of the Yangtze River Delta Region tended to cluster, the shape of built-up land became simpler, compactness improved, and fragmentation decreased. Cities with rapid expansion had simpler shapes and more compact structures, whereas cities with slower expansion had more complex shapes and higher fragmentation.

Providing a reference for a clearer understanding of the urbanization level of urban agglomerations, the findings of this study would be helpful to understanding the temporal and spatial evolution of cities, as well as the characteristics of landscape patterns at the scale of urban agglomerations. Such an understanding would help to provide a scientific basis for the planning, construction, and sustainable development of urban agglomerations.

Author Contributions: Conceptualization, Z.Y., L.C. and L.Y.; Formal analysis, Z.Y.; Funding acquisition, L.L.; Investigation, Z.Y. and S.S.; Methodology, Z.Y.; Project administration, L.C.; Supervision, L.C. and T.Z.; Visualization, L.L., R.L., Z.W. and J.Z.; Writing-original draft, Z.Y.; Writing-review and editing, Z.Y., L.C., L.L. and L.Y. All authors have read and agreed to the published version of the manuscript.

Funding: This research was funded by the National Natural Science Foundation of China (Grant No. 42001212).

Institutional Review Board Statement: Not applicable for this study.

Informed Consent Statement: Not applicable for this study.

Data Availability Statement: The input data used in this research can be accessed freely from online sources.

Acknowledgments: We would like to thank the Geographic Data Sharing Infrastructure, Resource and Environment Science, and Data Center (http:/ / www.resdc.cn accessed on 15 January 2021) for access to the data. We appreciate the editors and reviewers for their constructive comments and suggestions.

Conflicts of Interest: The authors declare no conflict of interest. 


\section{Appendix A}

Table A1. Full names and abbreviations of 41 cities in the YRDR.

\begin{tabular}{cccccc}
\hline City Name & Abbreviation & City Name & Abbreviation & City Name & Abbreviation \\
\hline Anqing & AQ & Jiaxing & JX & Suqian & SQ \\
Bengbu & BB & Jinhua & JH & Suzhou & SZ \\
Bozhou & BZ & Lishui & LS & Taizhou & TZ \\
Changzhou & CA & Lianyungang & LYG & Tongling & TL \\
Chizhou & CI & Luan & LA & Wenzhou & WZ \\
Chuzhou & CU & Lishui & LS & Wuxi & WX \\
Fuyang & FY & Maanshan & MAS & Wuhu & WH \\
Hangzhou & HZ & Nanjing & NJ & Xuzhou & XZ \\
Hefei & HF & Nantong & NT & Xuancheng & XC \\
Huzhou & HZ & Ningbo & NB & Yancheng & YC \\
Huaian & HA & Quzhou & QZ & Yangzhou & YZ \\
Huaibei & HB & Shanghai & SH & Zhenjiang & ZJ \\
Huainan & HN & Shaoxing & SX & Zhoushan & ZS \\
Huangshan & HS & Suzhou & SU & & \\
\hline
\end{tabular}

Table A2. Urban expansion speed indices of the YRDR.

\begin{tabular}{|c|c|c|c|c|c|c|}
\hline City & 1995-2000 & 2000-2005 & 2005-2010 & 2010-2015 & 2015-2018 & 1995-2018 \\
\hline $\mathrm{AQ}$ & 0.572 & 1.481 & 4.749 & 1.298 & 1.187 & 2.207 \\
\hline $\mathrm{BB}$ & 0.412 & 0.154 & 1.331 & 1.671 & 0.201 & 0.851 \\
\hline $\mathrm{BZ}$ & 0.436 & 0.134 & 0.966 & 0.997 & 0.865 & 0.702 \\
\hline$\overline{C A}$ & 1.558 & 3.062 & 7.179 & 0.814 & 3.388 & 4.072 \\
\hline $\mathrm{CI}$ & 0.938 & 0.918 & 10.794 & 2.527 & 2.181 & 4.448 \\
\hline $\mathrm{CU}$ & 2.654 & 0.329 & 1.951 & 2.935 & 0.821 & 2.107 \\
\hline $\mathrm{FY}$ & 0.705 & 0.311 & 0.979 & 0.651 & 1.353 & 0.804 \\
\hline $\mathrm{HZ}$ & 1.519 & 8.216 & 3.677 & 3.721 & 4.059 & 6.047 \\
\hline $\mathrm{HF}$ & 1.636 & 1.210 & 4.130 & 1.892 & 2.110 & 2.657 \\
\hline $\mathrm{HU}$ & 0.173 & 5.873 & 5.245 & 3.475 & 5.535 & 5.453 \\
\hline HA & 0.141 & 0.172 & 3.598 & 0.317 & 1.008 & 1.105 \\
\hline $\mathrm{HB}$ & 0.376 & 0.870 & 2.252 & 1.327 & 4.230 & 1.832 \\
\hline $\mathrm{HN}$ & 0.704 & 0.665 & 1.449 & 0.765 & 2.085 & 1.154 \\
\hline HS & 1.503 & 0.945 & 16.122 & 5.288 & -3.300 & 5.725 \\
\hline JX & 0.995 & 6.883 & 2.829 & 1.858 & 3.088 & 4.014 \\
\hline $\mathrm{JH}$ & 4.908 & 22.429 & 3.560 & 2.516 & 6.272 & 13.752 \\
\hline LS & 3.170 & 17.715 & 10.437 & 3.027 & 19.221 & 21.892 \\
\hline LYG & -0.110 & 0.190 & 3.354 & 0.180 & -3.386 & 0.273 \\
\hline LA & 0.335 & 0.619 & 1.562 & 1.660 & 3.324 & 1.504 \\
\hline MAS & 3.785 & 0.687 & 5.024 & 2.704 & -1.111 & 2.996 \\
\hline NJ & 2.547 & 1.993 & 6.694 & 0.378 & 2.917 & 3.623 \\
\hline NT & 0.935 & 2.408 & 15.322 & 5.508 & -1.033 & 6.782 \\
\hline NB & 1.754 & 14.744 & 1.732 & 3.049 & 1.234 & 6.321 \\
\hline QZ & 0.385 & 24.404 & 3.714 & 4.466 & 9.032 & 13.791 \\
\hline $\mathrm{SH}$ & 1.150 & 5.501 & 5.418 & 1.808 & 3.994 & 4.750 \\
\hline SX & 1.730 & 13.251 & 3.220 & 3.502 & 3.128 & 7.373 \\
\hline SU & 4.307 & 7.141 & 11.761 & 1.008 & 2.195 & 8.401 \\
\hline SQ & 0.255 & 0.079 & 3.590 & 0.363 & 0.727 & 1.077 \\
\hline $\mathrm{SZ}$ & 0.977 & 0.303 & 0.712 & 0.764 & 1.427 & 0.843 \\
\hline $\mathrm{TZ}$ & 0.940 & 13.164 & 2.894 & 7.325 & 9.443 & 10.802 \\
\hline TA & 0.915 & 1.359 & 6.728 & 1.591 & 1.746 & 3.024 \\
\hline $\mathrm{TL}$ & 0.559 & 0.940 & 7.401 & 2.472 & -6.099 & 1.538 \\
\hline WZ & 3.878 & 14.769 & 2.364 & 3.430 & 7.519 & 10.140 \\
\hline WX & 2.226 & 4.824 & 7.256 & 0.672 & 0.911 & 4.331 \\
\hline WH & 1.639 & 0.734 & 6.584 & 6.125 & -2.293 & 3.537 \\
\hline$X Z$ & 0.988 & 0.017 & 3.895 & 0.331 & 0.989 & 1.363 \\
\hline$X C$ & 1.651 & 0.788 & 7.951 & 6.823 & -2.108 & 4.242 \\
\hline YC & 1.061 & 0.557 & 2.170 & 0.937 & -4.674 & 0.347 \\
\hline$Y Z$ & 0.279 & 0.985 & 7.018 & 0.522 & 2.141 & 2.476 \\
\hline $\mathrm{ZJ}$ & 1.663 & 0.979 & 6.293 & 0.982 & 3.032 & 3.085 \\
\hline ZS & -2.880 & 8.704 & 1.921 & 0.190 & 34.233 & 7.632 \\
\hline
\end{tabular}




\section{References}

1. Li, S.; He, Y.; Xu, H.; Zhu, C.; Dong, B.; Lin, Y.; Si, B.; Deng, J.; Wang, K. Impacts of urban expansion forms on ecosystem services in urban agglomerations: A case study of Shanghai-Hangzhou Bay urban agglomeration. Remote Sens. 2021, 13, 1908. [CrossRef]

2. Lei, H.; Koch, J.; Shi, H. An analysis of spatio-temporal urbanization patterns in Northwest China. Land 2020, 9, 441. [CrossRef]

3. Zhu, C.; Zhang, X.; Wang, K.; Yuan, S.; Yang, L.; Skitmore, M. Urban-rural construction land transition and its coupling relationship with population flow in China's urban agglomeration region. Cities 2020, 101, 102701. [CrossRef]

4. Zhao, C.; Wu, Y.; Ye, X.; Wu, B.; Kudva, S. The direct and indirect drag effects of land and energy on urban economic growth in the Yangtze River Delta, China. Environ. Dev. Sustain. 2019, 21, 2945-2962. [CrossRef]

5. Han, J.; Meng, X.; Zhou, X.; Yi, B.; Liu, M.; Xiang, W.-N. A long-term analysis of urbanization process, landscape change, and carbon sources and sinks: A case study in China's Yangtze River Delta region. J. Clean. Prod. 2017, 141, 1040-1050. [CrossRef]

6. Han, J.; Liu, J. Urban spatial interaction analysis using inter-city transport big data: A case study of the Yangtze River Delta urban agglomeration of China. Sustainability 2018, 10, 4459. [CrossRef]

7. Liu, Y.Q.; Li, L.; Chen, L.Q.; Cheng, L.; Zhou, X.S.; Cui, Y.F.; Li, H.; Liu, W.Q. Urban growth simulation in different scenarios using the SLEUTH model: A case study of Hefei, East China. PLoS ONE 2019, 14, e0224998. [CrossRef] [PubMed]

8. Magarotto, M.G.; da Costa, M.F.; Tenedório, J.A.; Silva, C.P. Vertical growth in a coastal city: An analysis of Boa Viagem (Recife, Brazil). J. Coast. Conserv. 2016, 20, 31-42. [CrossRef]

9. Mandarino, A.; Pepe, G.; Cevasco, A.; Brandolini, P. Quantitative Assessment of Riverbed Planform Adjustments, Channelization, and Associated Land Use/Land Cover Changes: The Ingauna Alluvial-Coastal Plain Case (Liguria, Italy). Remote Sens. 2021, 13, 3775. [CrossRef]

10. Li, W.; Han, C.; Li, W.; Zhou, W.; Han, L. Multi-scale effects of urban agglomeration on thermal environment: A case of the Yangtze River Delta megaregion, China. Sci. Total Environ. 2020, 713, 136556. [CrossRef]

11. Wang, X.; Sun, X.; Tang, J.; Yang, X. Urbanization-induced regional warming in Yangtze River Delta: Potential role of anthropogenic heat release. Int. J. Climatol. 2015, 35, 4417-4430. [CrossRef]

12. Wu, Q.; Guo, R.; Luo, J.; Chen, C. Spatiotemporal evolution and the driving factors of PM2.5 in Chinese urban agglomerations between 2000 and 2017. Ecol. Indic. 2021, 125, 107491. [CrossRef]

13. Delia, K.A.; Haney, C.R.; Dyer, J.L.; Paul, V.G. Spatial analysis of a Chesapeake Bay Sub-Watershed: How land use and precipitation patterns impact water quality in the James River. Water 2021, 13, 1592. [CrossRef]

14. Hemmati, M.; Ellingwood, B.R.; Mahmoud, H.N. The Role of Urban Growth in Resilience of Communities Under Flood Risk. Earths Future 2020, 8, e2019EF001382. [CrossRef]

15. Chi, A. Human interference and environmental instability: Addressing the environmental consequences of rapid urban growth in Bamenda, Cameroon. Environ. Urban. 1998, 10, 161-174. [CrossRef]

16. Mbow, C.; Diop, A.; Diaw, A.T.; Niang, C.I. Urban sprawl development and flooding at Yeumbeul suburb (Dakar-Senegal). Afr. J. Environ. Sci. Technol. 2008, 2, 75-88.

17. Rojas, O.; Mardones, M.; Rojas, C.; Martinez, C.; Flores, L. Urban Growth and Flood Disasters in the Coastal River Basin of South-Central Chile (1943-2011). Sustainability 2017, 9, 195. [CrossRef]

18. Sahana, M.; Hong, H.; Sajjad, H. Analyzing urban spatial patterns and trend of urban growth using urban sprawl matrix: A study on Kolkata urban agglomeration, India. Sci. Total Environ. 2018, 628-629, 1557-1566. [CrossRef] [PubMed]

19. Yan, Y.; Ju, H.; Zhang, S.; Jiang, W. Spatiotemporal patterns and driving forces of urban expansion in coastal areas: A study on urban agglomeration in the Pearl River Delta, China. Sustainability 2020, 12, 191. [CrossRef]

20. Zeng, C.; Zhao, Z.; Wen, C.; Yang, J.; Lv, T. Effect of complex road networks on intensive land use in China's Beijing-Tianjin-Hebei urban agglomeration. Land 2020, 9, 532. [CrossRef]

21. Fang, C.; Yu, D. Urban agglomeration: An evolving concept of an emerging phenomenon. Landsc. Urb. Plan. 2017, 162, 126-136. [CrossRef]

22. Fu, Y.; Zhang, X. Mega urban agglomeration in the transformation era: Evolving theories, research typologies and governance. Cities 2020, 105, 102813. [CrossRef]

23. Chan, R.C.; Shimou, Y. Urbanization and sustainable metropolitan development in China: Patterns, problems and prospects. GeoJournal 1999, 49, 269-277. [CrossRef]

24. Pawe, C.K.; Saikia, A. Decumbent development: Urban sprawl in the Guwahati Metropolitan Area, India. Singap. J. Trop. Geogr. 2020, 41, 226-247. [CrossRef]

25. Kumar, A.; Pandey, A.C.; Hoda, N.; Jeyaseelan, A.T. Evaluating the Long-term Urban Expansion of Ranchi Urban Agglomeration, India Using Geospatial Technology. J. Indian Soc. Remote Sens. 2011, 39, 213-224. [CrossRef]

26. Mondal, B.; Das, D.N.; Bhatta, B. Integrating cellular automata and Markov techniques to generate urban development potential surface: A study on Kolkata agglomeration. Geocarto Int. 2017, 32, 401-419. [CrossRef]

27. Wang, J.; Fang, C.; Wang, Z. Advantages and dynamics of urban agglomeration development on Yangtze River Delta. J. Geogr. Sci. 2012, 22, 521-534. [CrossRef]

28. Liu, L.; Liu, J.; Liu, Z.; Xu, X.; Wang, B. Analysis on the spatio-temporal characteristics of urban expansion and the complex driving mechanism: Taking the Pearl River Delta urban agglomeration as a case. Complexity 2020, 2020, 8157143. [CrossRef]

29. Li, Y.; Liu, G. Characterizing spatiotemporal pattern of land use change and its driving force based on GIS and Landscape Analysis Techniques in Tianjin during 2000-2015. Sustainability 2017, 9, 894. [CrossRef] 
30. Zhao, X.; Zhang, M.; Li, Y.; Huang, X.; Wang, B.; Zhang, L. Urban residential land expansion and agglomeration in China: A spatial analysis approach. Environ. Dev. Sustain. 2020, 22, 5317-5335. [CrossRef]

31. Wang, Z.; Fang, C.; Zhang, X. Spatial expansion and potential of construction land use in the Yangtze River Delta. J. Geogr. Sci. 2015, 25, 851-864. [CrossRef]

32. Zhu, J.; Ding, N.; Li, D.; Sun, W.; Xie, Y.; Wang, X. Spatiotemporal Analysis of the Nonlinear Negative Relationship between Urbanization and Habitat Quality in Metropolitan Areas. Sustainability 2020, 12, 669. [CrossRef]

33. Yu, X.; Wu, Z.; Zheng, H.; Li, M.; Tan, T. How urban agglomeration improve the emission efficiency? A spatial econometric analysis of the Yangtze river delta urban agglomeration in China. J. Environ. Manag. 2020, 263, 110061. [CrossRef]

34. Tenedório, J.A.; Rebelo, C.; Estanqueiro, R.; Henriques, C.D.; Marques, L.; Gonçalves, J.A. New Developments in Geographical Information Technology for Urban and Spatial Planning. In Technologies for Urban and Spatial Planning: Virtual Cities and Territories; IGI Global: Hershey, PA, USA, 2014; pp. 196-227. [CrossRef]

35. Yu, W.; Zhou, W. The spatiotemporal pattern of urban expansion in China: A comparison study of three urban megaregions. Remote Sens. 2017, 9, 45. [CrossRef]

36. Peng, J.; Liu, Y.; Shen, H.; Xie, P.; Hu, X.; Wang, Y. Using impervious surfaces to detect urban expansion in Beijing of China in 2000s. Chin. Geogr. Sci. 2016, 26, 229-243. [CrossRef]

37. Chen, M.; Zhou, Y.; Hu, M.; Zhou, Y. Influence of urban scale and urban expansion on the urban heat island effect in Metropolitan areas: Case study of Beijing-Tianjin-Hebei urban agglomeration. Remote Sens. 2020, 12, 3491. [CrossRef]

38. Kim, S. Urban development and landscape change in the Yangtze River Delta region in China. Int. J. Sustain. Dev. World Ecol. 2019, 26, 141-153. [CrossRef]

39. Xu, G.; Jiao, L.; Liu, J.; Shi, Z.; Zeng, C.; Liu, Y. Understanding urban expansion combining macro patterns and micro dynamics in three Southeast Asian megacities. Sci. Total Environ. 2019, 660, 375-383. [CrossRef]

40. Zhang, D.-D.; Zhang, L. Land cover change in the central region of the lower Yangtze River based on Landsat imagery and the Google Earth Engine: A case study in Nanjing, China. Sensors 2020, 20, 2091. [CrossRef] [PubMed]

41. Fei, W.; Zhao, S. Urban land expansion in China's six megacities from 1978 to 2015. Sci. Total Environ. 2019, 664, 60-71. [CrossRef]

42. Luo, J.; Xing, X.; Wu, Y.; Zhang, W.; Chen, R.S. Spatio-temporal analysis on built-up land expansion and population growth in the Yangtze River Delta Region, China: From a coordination perspective. Appl. Geogr. 2018, 96, 98-108. [CrossRef]

43. Sun, W.; Shan, J.; Wang, Z.; Wang, L.; Lu, D.; Jin, Z.; Yu, K. Geospatial analysis of urban expansion using remote sensing methods and data: A case study of Yangtze River Delta, China. Complexity 2020, 3239471. [CrossRef]

44. Ye, C.; Zhu, J.J.; Li, S.M.; Yang, S.; Chen, M.X. Assessment and analysis of regional economic collaborative development within an urban agglomeration: Yangtze River Delta as a case study. Habitat Int. 2019, 83, 20-29. [CrossRef]

45. Du, H.; Wang, D.; Wang, Y.; Zhao, X.; Qin, F.; Jiang, H.; Cai, Y. Influences of land cover types, meteorological conditions, anthropogenic heat and urban area on surface urban heat island in the Yangtze River Delta Urban Agglomeration. Sci. Total Environ. 2016, 571, 461-470. [CrossRef] [PubMed]

46. Cheng, L.; Li, L.; Chen, L.; Hu, S.; Yuan, L.; Liu, Y.; Cui, Y.; Zhang, T. Spatiotemporal Variability and Influencing Factors of Aerosol Optical Depth over the Pan Yangtze River Delta during the 2014-2017 Period. Int. J. Environ. Res. Public Health 2019, 16, 3522. [CrossRef] [PubMed]

47. Xu, Y.; Xu, Y.; Wang, Y.; Wu, L.; Li, G.; Song, S. Spatial and temporal trends of reference crop evapotranspiration and its influential variables in Yangtze River Delta, eastern China. Theor. Appl. Climatol. 2017, 130, 945-958. [CrossRef]

48. Liu, J.Y.; Liu, M.L.; Tian, H.Q.; Zhuang, D.F.; Zhang, Z.X.; Zhang, W.; Tang, X.M.; Deng, X.Z. Spatial and temporal patterns of China's cropland during 1990-2000: An analysis based on Landsat TM data. Remote Sens. Environ. 2005, 98, 442-456. [CrossRef]

49. Liu, J.; Liu, M.; Deng, X.; Zhuang, D.; Zheng, Z.; Luo, D. The land use and land cover change database and its relative studies in China. J. Geogr. Sci. 2002, 12, 275-282.

50. Wu, W.; Zhao, S.; Zhu, C.; Jiang, J. A comparative study of urban expansion in Beijing, Tianjin and Shijiazhuang over the past three decades. Landsc. Urb. Plan. 2015, 134, 93-106. [CrossRef]

51. Guang, X.; Fang, C.; Zhou, M.; Wu, H. Spatial and temporal characteristics of spatial expansion of urban land in Wuhan urban agglomeration. J. Nat. Resour. 2012, 27, 1147-1459.

52. Wang, H.; Zhang, B.; Liu, Y.; Liu, Y.; Xu, S.; Zhao, Y.; Chen, Y.; Hong, S. Urban expansion patterns and their driving forces based on the center of gravity-GTWR model: A case study of the Beijing-Tianjin-Hebei urban agglomeration. J. Geogr. Sci. 2020, 30, 297-318. [CrossRef]

53. Wu, X.; Fang, X.; Miao, Y.; Wang, K.; Pang, C. Study on urban expansion of Hefei city based on Landsat data. J. Zhejiang Univ. 2017, 44, 631-639. [CrossRef]

54. Zeng, C.; Liu, Y.; Stein, A.; Jiao, L. Characterization and spatial modeling of urban sprawl in the Wuhan metropolitan area, China. Int. J. Appl. Earth Obs. Geoinf. 2015, 34, 10-24. [CrossRef]

55. Liu, X.; Dong, G.; Wang, X.; Xue, Z.; Jiang, M.; Lu, X.; Zhang, Y. Characterizing the spatial pattern of marshlands in the Sanjiang Plain, Northeast China. Ecol. Eng. 2013, 53, 335-342. [CrossRef]

56. Madasa, A.; Orimoloye, I.R.; Ololade, O.O. Application of geospatial indices for mapping land cover/use change detection in a mining area. J. Afr. Earth Sci. 2021, 175, 104108. [CrossRef]

57. Liu, Y.; Cao, X.; Li, T. Identifying driving forces of built-up land expansion based on the geographical detector: A case study of Pearl River Delta urban agglomeration. Int. J. Environ. Res. Public Health 2020, 17, 1759. [CrossRef] [PubMed] 
58. Feng, D.; Bao, W.; Fu, M.; Zhang, M.; Sun, Y. Current and future land use characters of a national central city in eco-fragile region-A case study in Xi'an city based on FLUS model. Land 2021, 10, 286. [CrossRef]

59. Tian, Y. Mapping suburbs based on spatial interactions and effect analysis on ecological landscape change: A case study of Jiangsu Province from 1998 to 2018, Eastern China. Land 2020, 9, 159. [CrossRef]

60. Wadduwage, S.; Millington, A.; Crossman, N.D.; Sandhu, H. Agricultural Land Fragmentation at Urban Fringes: An Application of Urban-To-Rural Gradient Analysis in Adelaide. Land 2017, 6, 28. [CrossRef]

61. Padmanaban, R.; Bhowmik, A.K.; Cabral, P.; Zamyatin, A.; Almegdadi, O.; Wang, S. Modelling urban sprawl using remotely sensed data: A case study of Chennai city, Tamilnadu. Entropy 2017, 19, 163. [CrossRef]

62. Wang, J.; Li, L.; Zhang, T.; Chen, L.Q.; Wen, M.X.; Liu, W.Q.; Hu, S. Optimal Grain Size Based Landscape Pattern Analysis for Shanghai Using Landsat Images from 1998 to 2017. Pol. J. Environ. Stud. 2021, 30, 2799-2813. [CrossRef]

63. Li, H.; Li, L.; Chen, L.Q.; Zhou, X.S.; Cui, Y.F.; Liu, Y.Q.; Liu, W.Q. Mapping and characterizing spatiotemporal dynamics of impervious surfaces using Landsat images: A case study of Xuzhou, East China from 1995 to 2018. Sustainability 2019, 11, 1224. [CrossRef]

64. Sung, C.-H.; Liaw, S.-C. Using spatial pattern analysis to explore the relationship between vulnerability and resilience to natural hazards. Int. J. Environ. Res. Public Health 2021, 18, 5634. [CrossRef] [PubMed]

65. Ke, X.L.; Wang, X.Y.; Guo, H.X.; Yang, C.; Zhou, Q.; Mougharbel, A. Urban ecological security evaluation and spatial correlation researchbased on data analysis of 16 cities in Hubei Province of China. J. Clean. Prod. 2021, 311, 127613. [CrossRef]

66. Cui, Y.F.; Li, L.; Chen, L.Q.; Zhang, Y.; Cheng, L.; Zhou, X.S.; Yang, X.Y. Land-Use Carbon Emissions Estimation for the Yangtze River Delta Urban Agglomeration Using 1994-2016 Landsat Image Data. Remote Sens. 2018, 10, 1334. [CrossRef]

67. Wang, N.; Li, J.; Duan, L.; Chen, C.; Gao, Y.; Fan, P. Comparative study on the urban sprawl and its driving force in two Metropolitan areas, Yangtze River Delta and Central Plains. J. Henan Univ. 2017, 47, 681-692. [CrossRef]

68. Zhao, S.; Zhou, D.; Zhu, C.; Qu, W.; Zhao, J.; Sun, Y.; Huang, D.; Wu, W.; Liu, S. Rates and patterns of urban expansion in China's 32 major cities over the past three decades. Landsc. Ecol. 2015, 30, 1541-1559. [CrossRef]

69. Qian, Z.; Fu, H.; Wang, Y.; Zhang, Y. Characteristics of urban expansion and morphological evolution in Nanjing from 2004 to 2016. Remote Sens. Land Resour. 2019, 31, 149-156. [CrossRef]

70. Tong, C.; Cheng, L.; Yunjian, L. Changes in landscape pattern of built- up land and its driving factors during urban sprawl. Acta Ecol. Sin. 2020, 40, 3283-3294. [CrossRef]

71. Liu, Y.; He, Q.; Tan, R.; Liu, Y.; Yin, C. Modeling different urban growth patterns based on the evolution of urban form: A case study from Huangpi, Central China. Appl. Geogr. 2016, 66, 109-118. [CrossRef]

72. Hu, P.; Li, F.; Hu, D.; Sun, X.; Liu, Y.; Chen, X. Spatial and temporal characteristics of urban expansion in Pearl River Delta urban agglomeration from 1980 to 2015. Acta Ecol. Sin. 2021, 41, 1-11. [CrossRef] 